\title{
基于 MK60DN512Z 微控制器的电磁智能车控制系统设计
}

\author{
MK60DN512Z Microcontroller \\ 周鹏超 王霆 苗泉利 \\ Pengchao Zhou Ting Wang Quanli Miao
}

Design of Electromagnetic Intelligent Vehicle Control System Based on

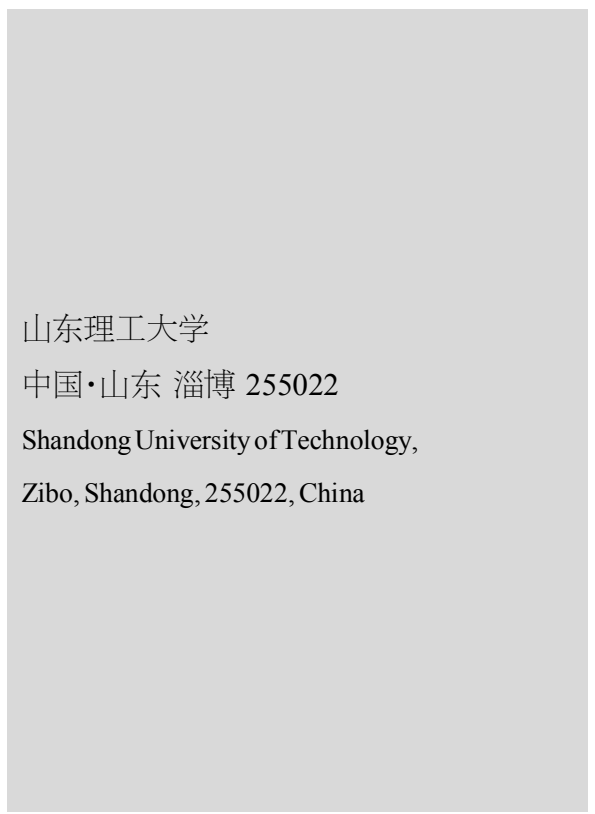

【摘要】文章设计了一种基于 MK60DN512Z微控制器和电磁传感器的智能车控制系统, 系统集成了电机驱动模块、车速检测模块及信号采集放大模块, 采用六路 $10 \mathrm{mH}$ 工字电感 对电磁信号进行检测, 经过滤波、放大和检波后返回微控制器, 采用 PD 控制和 PID 控制算 法对舵机转角量和电机转速进行控制, 实现了系统对电磁信号的自动检测和行驶路径的 优化。

【Abstract】This paper designs an intelligent vehicle control system based on MK60DN512Z microcontroller and electromagnetic sensor. The system integrates motor drive module, speed detection module and signal acquisition and amplification module. Six 10mH I-shaped inductors are used to detect electromagnetic signals, which are filtered, amplified and detected before being returned to the microcontroller. PD control and PID control algorithm are used to control steering gear rotation angle and motor rotation speed, thus realizing automatic detection of electromagnetic signals and optimization of driving path.

【关键词】智能车; 控制; 电磁信号检测

【Keywords】smart car; control; electromagnetic signal detection

【DOI】10.36012/etr.v2i3.1426

\section{1 引言}

论文所述的电磁智能车控制系统基于 MK60DN512Z 微 控制器, 以六路 $10 \mathrm{mH}$ 工字电感作为传感器对电磁信号进行 采集, 微控制器通过电磁信号判断系统与赛道中线的相对位 置, 控制舵机和电机运转, 实现系统的稳定运行。

\section{2 硬件系统设计}

\section{1 电源管理模块}

电源管理模块采用 $7.4 \mathrm{~V} 、 3000 \mathrm{~mA}$ 的锂电池供电, 经过不 同的线性稳压电源电路,得到适合各模块正常工作的电压值。 其中, 由 AMS1117-3.3V 芯片输出的电压供给 MK60 最小系 统、OLED 显示屏, 由 LM7806 芯片输出的 $6 \mathrm{~V}$ 电压给舵机供 电, 由 LM2940 芯片输出的 $5 \mathrm{~V}$ 电压给编码器、陀螺仪、蓝牙以
及电磁信号检测模块等供电 ${ }^{[1]}$ 。

\section{2 电机驱动模块}

电机驱动模块采用 MOS 管 $\mathrm{H}$ 桥驱动方案。每两个 MOS 管组成振荡, IR2104S 驱动芯片驱动两个 $\mathrm{N}$ 沟道 MOSFET 形 成半桥驱动电路, 同时采用八路正相高速驱动芯片 74HC244, 隔离单片机和驱动电路之间的信号流通, 防止单片机烧毁。

\section{3 电磁信号采集及放大模块}

电磁信号采集传感器由对称分布在车模两侧不同位置的 6 个 $10 \mathrm{mH}$ 工字电感和 $6.8 \mathrm{nF}$ 的校正电容构成。赛道电源使用 $100 \mathrm{~mA} 、 20 \mathrm{kHz}$ 的交变电源信号, 当智能小车系统置于通电引 导线附近时, 工字电感中的线圈会产生感应电动势。但由此采 集到的电磁感应信号十分微弱, 且信号噪声较大, 不能直接使 
效减少了后期道岔调试、轨面起道的工作量, 节省了大量的封 锁时间, 为施工质量提供有力保证。数据表明,应用新工艺不 但能保质保量完成生产任务, 还能达到提质增效效益。

表 2 走行轨施工工艺改进前后效果对比

\begin{tabular}{c|c|c}
\hline 大面抄平施工 & 改进前 & 改进后 \\
\hline 大面抄平高差 & $\begin{array}{c}\text { 道贫前后高差明显, } \\
\text { 最大高差达 } 150 \mathrm{~mm}\end{array}$ & $\begin{array}{l}\text { 道忿前后高差小,部分测量 } \\
\text { 困难地段高差小于 } 50 \mathrm{~mm}\end{array}$ \\
\hline 施工时长 & $45 \mathrm{~min}$ & $30 \mathrm{~min}$ \\
\hline 劳力消耗 & 职工 5 人、劳务工 4 人 & 职工 3 人、劳务工 2 人 \\
\hline 后期配合时间 & $20 \mathrm{~min}$ & $5 \mathrm{~min}$ \\
\hline
\end{tabular}

\section{7 结语}

通过对道岔大修施工作业过程中大面抄平工艺的改进, 采用新型激光水准仪配合新工艺进行大面抄平，可以简单高 效地完成施工任务, 提高作业有效率和施工安全性。道岔大修 质量进一步提高，对道盆设备的基床病害能起到较好的预防 整治作用。

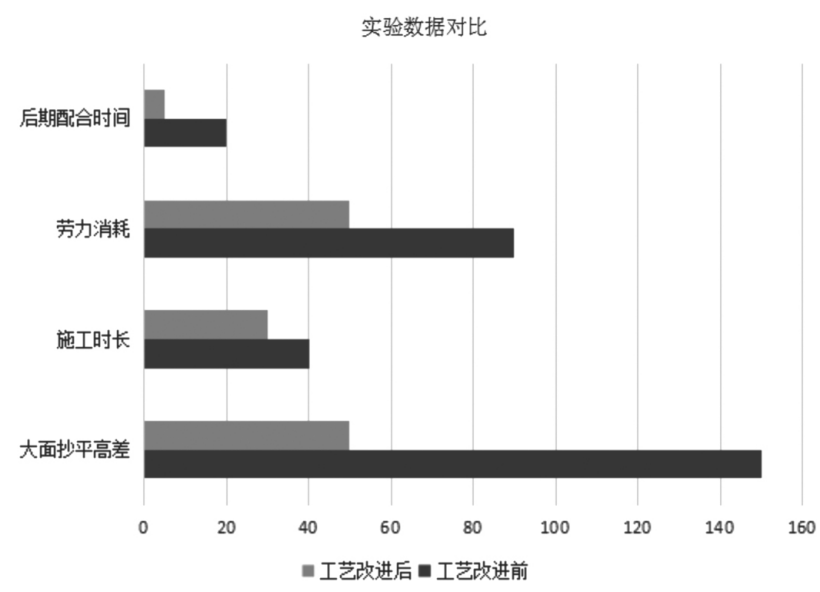

图 3 新旧工艺数据统计

参考文献

[1]敬劲松.成组更换道岔施工组织[J].科技信息,2011(7):238+270.

[2]李长伟.铁路既有线成组更换道岔施工技术探讨 [J].科技与创 新,2017(3):66+69.

\section{（上接第 158 页）}

用。本系统选择集成运算放大芯片 OPA2350 对采集到的微弱 电磁信号进行放大, 并通过滤波、检波电路对采集的交变信号 进行整定 (见图 1), 以供 MK60 微控制器使用。

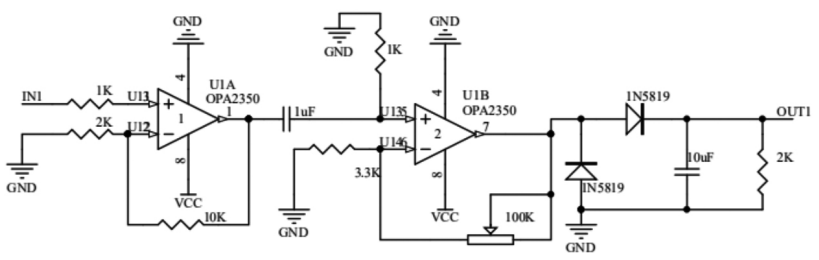

图 1 电磁信号放大电路

\section{3 软件系统设计}

\section{1 电磁信号的采集转换}

在采集信号时, 对同一位置的信号进行多次采集组成数 组, 采集数组固定长度为 $\mathrm{N}$, 每次采集到的信号值都储存在数 组最后的数据单元, 处理数据时去除采集数组的前五次和最 后五次采集值, 以削减采集信号的离散性,对数组从前到后使 用加权递减的方式取得平均值, 此平均值即为该点采集的电 磁信号值。

\section{2 车速控制}

系统的车速控制策略采用模糊控制 PID 算法。以编码器
的车速采回值作为控制参量, MK60 微控制器的 PWM 信号速 度输出量和编码器采回的实际车速之差即为控制偏差量。预 先设定一个信号采集周期供系统工作，再通过 PID 基本公式 得到整个被控过程的比例系数、积分时间和微分时间的值，以 此对 PID 控制系统的参量进行整定。

\section{3 转向控制}

为了使系统能够更好地对赛道最优路径进行判定, 先将 左右两端水平对称放置电感的电磁信号值作为一个方向控制 的偏差值, 当此偏差值为 0 时, 左右两个水平电感的采回值相 等, 系统处于赛道中线位置, 路径最优。本系统的方向控制策 略就是在车模行驶过程中, 不断计算此偏差值, 判断系统与赛 道中心线的相对位置。系统的转向控制最终通过 S3010 舵机 实现。

\section{4 结语}

论文从硬件系统设计和软件系统设计两个方面详细介绍 了基于 MK60DN512Z 微控制器的智能车控制系统设计方案, 经实践验证，依据上述方案设计的控制系统能够稳定地运行。

\section{参考文献}

[1]卓晴,黄开胜,邵贝贝.学做智能车 - 挑战“飞思卡尔”杯 $[\mathrm{M}]$. 北 京:北京航空航天大学出版社,2007. 